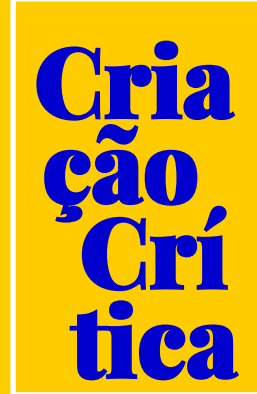

\title{
SIMBOLISMO E MODERNISMO NA ILUSTRAÇÃO LITERÁRIA DE HARRY CLARKE ${ }^{1}$
}

Fabricio Vaz Nunes ${ }^{2}$

\begin{abstract}
RESUMO: Este trabalho aborda a obra do artista irlandês Harry Clarke (1889-1931), buscando demonstrar a especificidade dos aspectos simbolistas e decadentistas presentes na sua ilustração literária, marcada pela influência do ilustrador inglês Aubrey Beardsley e diretamente ligada ao contexto nacionalista do Irish Revival e do movimento Arts and Crafts irlandês. Como ilustrador, Clarke foi um intérprete, no meio visual, de textos essenciais para o simbolismo de língua inglesa, como A balada do velho marinheiro, de Samuel Taylor Coleridge e os Contos de mistério e imaginação de Edgar Allan Poe, incluindo a poesia nacionalista e medievalizante da primeira fase de William Butler Yeats. Por outro lado, afastando-se do simbolismo profético de Yeats, Clarke também ilustrou textos que problematizavam a dimensão nacionalista do Irish Revival, como a polêmica peça The playboy of the western world, do dramaturgo irlandês John Millington Synge. A análise das relações estabelecidas entre as ilustrações, os textos literários e o seu contexto cultural caracteriza a obra de Harry Clarke como manifestação de um decadentismo tardio dentro do qual eclodem aspectos marcadamente modernos, presentes nas imagens deformantes e insólitas criadas para a edição de 1925 do Fausto de Goethe.

PALAVRAS-CHAVE: Harry Clarke (1889-1931), ilustração de livros, literatura anglo-irlandesa.
\end{abstract}

\section{SYMBOLISM AND MODERNISY IN HARRY CLARKE'S LITERARY ILLUSTRATIONS}

\begin{abstract}
This paper examines the work of Irish artist Harry Clarke (1889-1931), aiming to show the specificity of the symbolist and decadent aspects in his literary illustrations, marked by the influence of the English illustrator Aubrey Beardsley and directly linked to the nationalist context of the Irish Revival and the Irish Arts and Crafts Movement. As an illustrator, Clarke created visual interpretations of literary works that are essential to the Symbolist movement in the English language, such as The rime of the ancient mariner by Samuel Taylor Coleridge and the Tales of mystery and imagination by Edgar Allan Poe, including the nationalist and medievalizing early poetry of William Butler Yeats. On the other hand, setting himself apart from Yeats's prophetic symbolism, Clarke also illustrated works that problematized the nationalist dimension of the Irish Revival, such as the polemic play The playboy of the western world by John Millington Synge. The analysis of the relationships between the illustrations, the literary works and their cultural context characterize Harry Clarke's work as a manifestation of a late decadentism in which distinctly modernist aspects are brought forth, as shown in the deforming and eerie images created for the 1925 edition of Goethe's Faust.

KEYWORDS: Harry Clarke (1889-1931), book illustration, Anglo-Irish literature.
\end{abstract}

\footnotetext{
${ }^{1}$ Este artigo é um desdobramento da pesquisa desenvolvida no âmbito do Estágio Pós-doutoral na Faculdade de Letras da Universidade Federal de Minas Gerais (FALE/UFMG), com apoio da Coordenação de Aperfeiçoamento de Pessoal de Nível Superior - Brasil (CAPES) - Código de Financiamento 001.

${ }^{2}$ Mestre em História da Arte e da Cultura pela Universidade Estadual de Campinas e doutor em Estudos Literários pela Universidade Federal do Paraná. Professor adjunto na Universidade Estadual do Paraná - Campus I - Escola de Música e Belas Artes do Paraná, na área de História da Arte.
} 


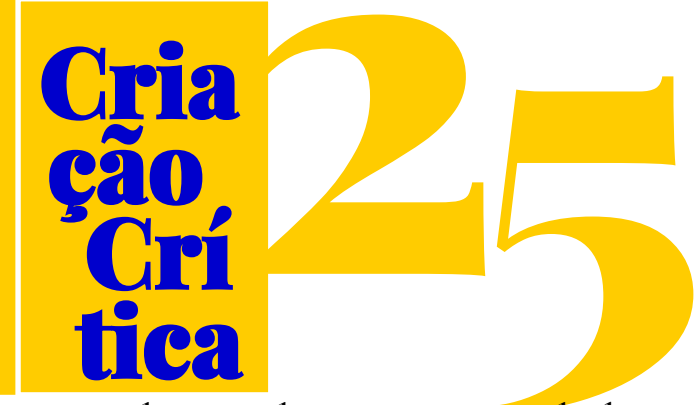

1913 que a influência do ilustrador passa a se manifestar, por exemplo, nas ilustrações que Clarke realizou para o poema de W. B. Yeats, "The song of wandering Aengus". Em uma destas ilustrações (fig. 1), vê-se uma bela figura feminina que levita, envolta em um manto decorado com padrões espiralados e florais formados por minúsculos pontos, elementos visuais empregados frequentemente por Beardsley e adotados por Clarke, que os emprega de forma talvez ainda mais detalhista e microscópica. A imagem evoca a segunda estrofe do poema, em que o peixe capturado por Aengus e deixado no chão se transforma em uma fantástica aparição feminina:

When I had laid it on the floor

I went to blow the fire a-flame

But something rustled on the floor,

And someone called me by my name:

It had become a glimmering girl

With apple blossom in her hair

Who called me by my name and ran

And faded through the brightening air (YEATS, 2015, pos. $\left.1232^{3}\right){ }^{4}$

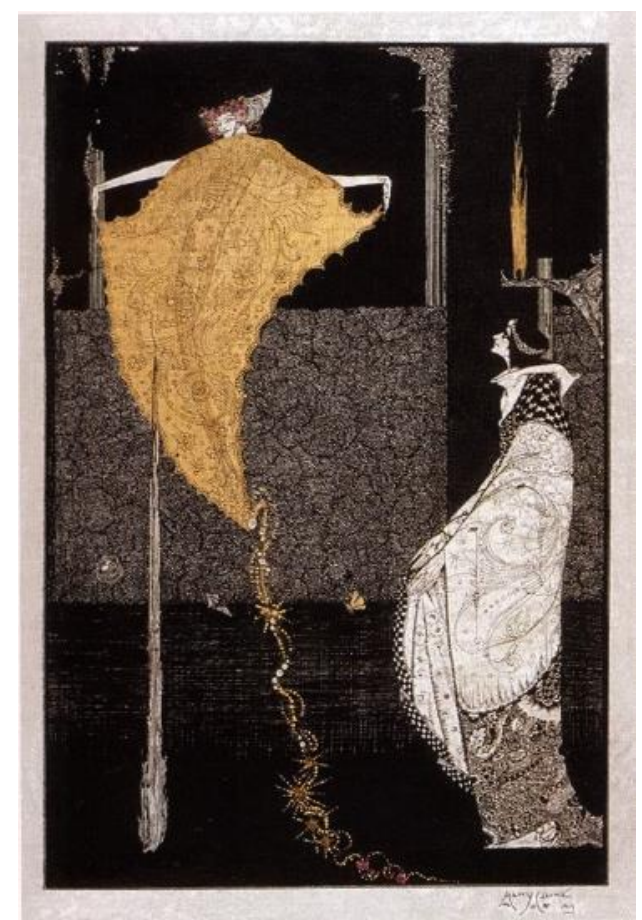

Fig. 1. Harry Clarke, ilustração para "The song of wandering Aengus", 1913.

A beleza etérea da jovem contemplada por Aengus, cujo corpo aparece indefinido, oculto pela veste que se eleva no espaço - referência ao seu desaparecimento no "ar cintilante", no poema -,

\footnotetext{
${ }^{3}$ Incluímos a indicação "pos." para indicar a posição no texto em e-books que não possuem numeração de página.

4 "Quando tinha deixado o peixe no chão /As chamas do fogo fui assoprar / Mas algo fez som como folhas no chão / E alguém pelo nome ouvi me chamar: / Ele fez-se uma moça que bruxuleava / Com flor de maçã no cabelo enfeitado / Que me chamou pelo nome e correu / E sumiu em meio ao ar cintilante" (Tradução livre do autor, doravante indicada por [T.L.]).
} 

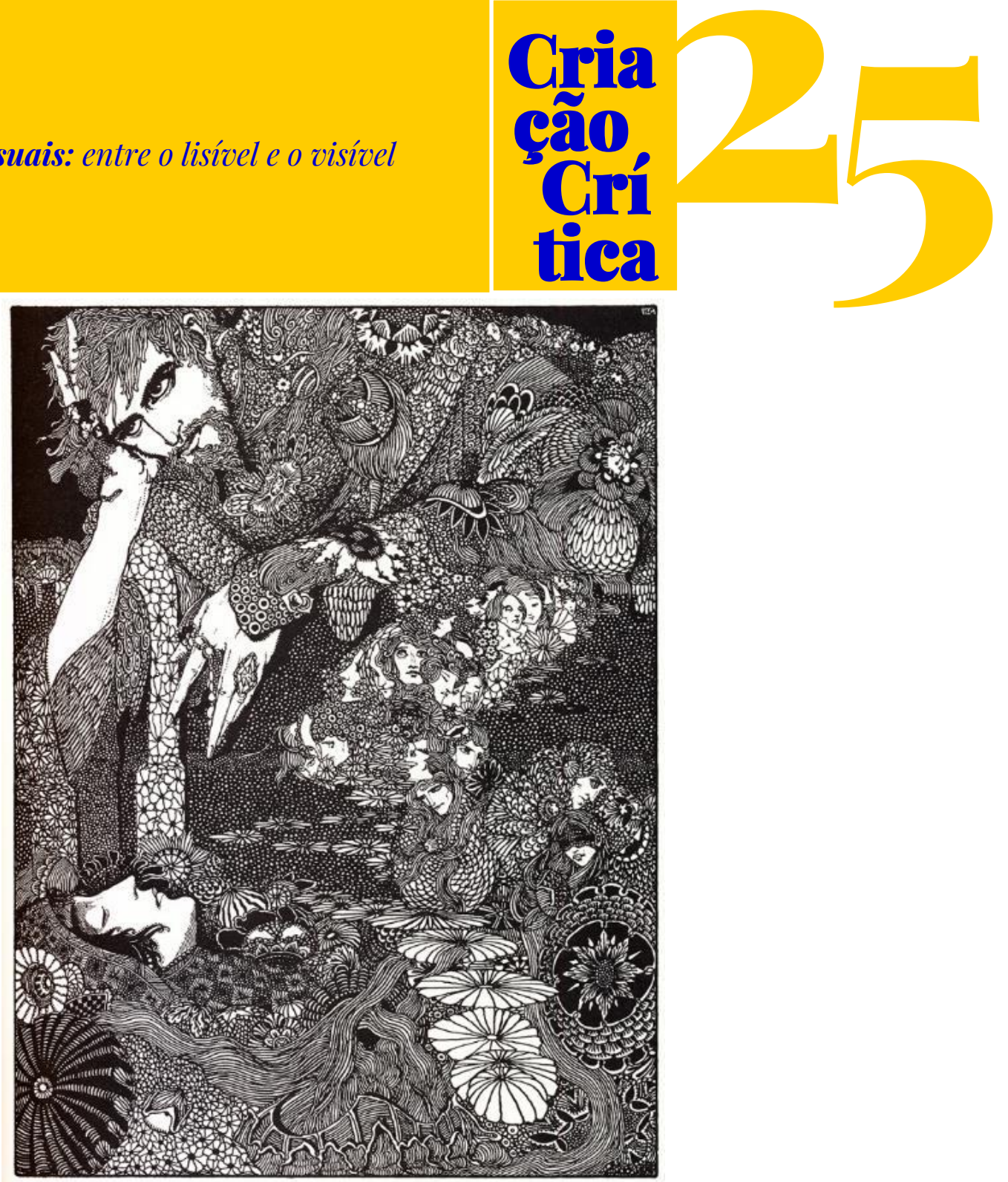

Fig. 3. Harry Clarke, ilustração para "Morella", de Tales of mystery and imagination, 1918.

A interpretação que Clarke realiza das narrativas de Poe é marcada pelo uso extensivo de padronagens gráficas, em que o acúmulo de formas florais, marinhas, orgânicas em geral, ou ainda geometricamente elaboradas, presentes em elementos de vestuário ou de arquitetura, faz submergir os elementos propriamente figurativos e narrativos de cada imagem. A obsessão pelo excesso, pela saturação dos sentidos, é um elemento decisivo na poética visual das ilustrações para Tales of mystery and imagination: Harry Clarke ilustra Poe no mesmo espírito que anima o Des Esseintes de $\grave{A}$ rebours, de Joris-Karl Huysmans, o texto fundamental do decadentismo, que ele quase chegou a ilustrar, sendo impedido pelas dificuldades impostas pela doença que o levaria à morte em 1931. Na ilustração para "Morella" (fig. 3), por exemplo, a personagem feminina que jaz, morta ou adormecida, na seção inferior da imagem, converte-se em uma orgia de reprodução vegetal, à medida que seu corpo como que se converte em uma floração de rostos femininos, sugerindo a continuidade anímica da amante do protagonista através da reprodução biológica - marcada, estilisticamente, pelo excesso, pela saturação, pela profusão envolvente de flores e padrões vegetais e orgânicos. Como no colecionismo decadente e luxuoso retratado em À rebours, trata-se de uma "coleção" de elementos decorativos levada ao extremo, recobrindo o próprio narrador, que pouco se distingue do fundo de grafismos florais. Além disso, a repetição rítmica e variada das formas vegetais parece realizar o famoso ideal de correspondência entre as artes, fazendo ressoar no elemento gráfico a repetição do nome da amada do protagonista e narrador, que gradativamente percebe a reencarnação da defunta Morella na filha: 


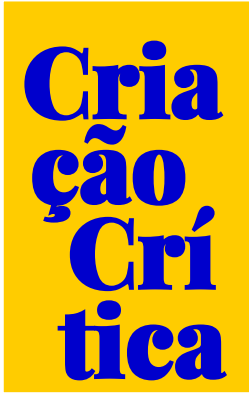

por todos como Lilly, havia aprendido a arte do bordado com a irmã de William Morris - um dos principais integrantes do movimento Arts and Crafts na Inglaterra - para cuja família também Elizabeth (conhecida como Lolly) havia trabalhado. A Dun Emer Guild promoveu a produção na área dos têxteis e da editoração artesanal de livros, nos moldes preconizados por Morris, mas introduzindo o elemento nacionalista, que ia desde a escolha dos materiais, passando pela mão de obra e pelos elementos estilísticos, como era afirmado no prospecto impresso pela guilda em 1903:

A wish to find work for Irish hands in the making of beautiful things was the
beginning of Dun Emer... The idea is to make beautiful things; this, of course,
means materials honest and true \& the application to them of deftness of hand,
brightness of colour, and cleverness of design.
Everything as far as possible, is Irish: the paper of the books, the linen of the
embroidery and the wool of the tapestry and carpets. The designs as also of the
spirit and tradition of the country (apud LARMOUR, 1992, p.152).

Harry Clarke, no entanto, pertencia a outra geração de artistas. Embora ele tivesse participado diretamente das atividades da Arts and Crafts Society of Ireland, a apropriação que realizou de um elemento visual tão reconhecidamente ligado às tradições irlandesas como o entrelaçado celta efetuava a transposição de um contexto religioso, em que o entrelaçado assumia uma função de devoção e organização estética das páginas do livro sagrado, para o contexto profano do conto de Poe, em que se tornava sinal da dissolução da realidade empírica e da subversão das leis naturais. Deve-se destacar, ainda, que a postura artística de Clarke sempre foi mais internacionalizante, principalmente na ilustração literária: ao contrário do vitral (predominantemente de caráter religioso), que fica preso à localização geográfica da construção, a ilustração pode alcançar o público, virtualmente, em qualquer local; além disso, todos os editores de Clarke eram ingleses, e seus livros eram publicados tanto na Irlanda e na Inglaterra como nos Estados Unidos, em que tanto as filiais das editoras quanto os emigrados irlandeses tinham grande poder de atuação. A recuperação de elementos nacionais, assim, era considerada por Clarke de maneira crítica, incluindo também a necessidade de se criar uma linguagem que fosse simultaneamente nacional e capaz de apresentar-se diante do mundo contemporâneo, ou seja, que fosse ao mesmo tempo irlandesa e moderna, e a literatura internacional, nesse sentido, era um campo privilegiado de atuação artística. Como percebe Marguerite Helmers, "[...] Harry Clarke's illustrations blended international modernism with the nineteenth-century aesthetics of the Celtic Revival and Arts and Crafts movements" (HELMERS, 2016, p. 23). ${ }^{8}$

A posição de Clarke, assim, diverge das visões artísticas de Yeats: ainda que o artista e o escritor tenham tido amigos em comum e tenham colaborado nas escolhas literárias para a Geneva Window (1929), que ilustra a obra de vários escritores modernos irlandeses, Harry Clarke tinha suas reservas quanto ao escritor consagrado, como manifestou em uma carta ao amigo e crítico de arte Thomas Bodkin sobre uma produção teatral no Abbey Theater: "I know exactly how I feel about

\footnotetext{
7 "Um desejo de arranjar trabalho para mãos irlandesas na fabricação de coisas belas foi o começo de Dun Emer... A ideia é fabricar coisas belas; isso, é claro, significa materiais honestos e verdadeiros e a aplicação nestes de destreza manual, brilho de cor e inteligência no desenho.

Tudo, o tanto quanto for possível, é irlandês; o papel dos livros, o linho dos bordados e a lã da tapeçaria e dos tapetes. Os desenhos, também no espírito e tradição do país [T.L.].

8 "As ilustrações de Harry Clarke fundiam o modernismo internacional com a estética oitocentista dos movimentos do Celtic Revival e do Arts and Crafts" [T.L.].
} 


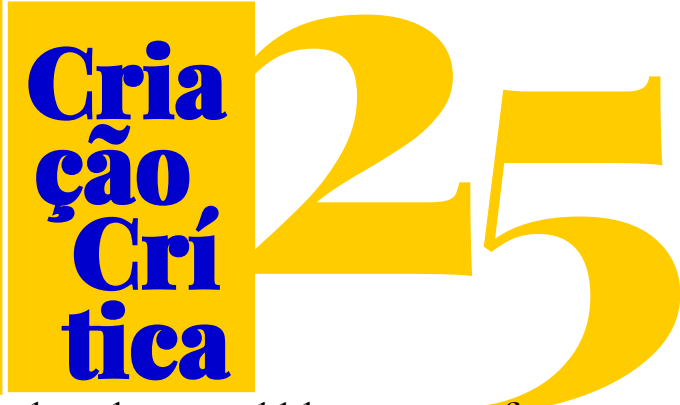

Yeats and would not consider the business for one instant if I thought I would have to conform in any way to his 'Art' views and guff about composition and colour" (apud BOWE, 2015, p. 148). ${ }^{9}$ A postura de Clarke a respeito de Yeats parece ter passado por mudanças ao longo da sua vida; Nicola Gordon Bowe, no entanto, assim resume a sua postura diante das utopias do Irish Revival, em que se destaca a dimensão decadentista: "He was a decadent in the decorative, symbolist, Gothic sense, but without Yeats' prophetic Symbolism" (BOWE, 2015, p. 156). ${ }^{10}$

Neste sentido, é significativo que um dos seus autores irlandeses mais recorrentes tenha sido John Millington Synge, autor, dentre outras obras, de The Aran Islands e The playboy of the western world (ambas obras de 1907). A vivaz descrição das ilhas Aran - lugar onde ainda se fala, até os dias de hoje, o gaélico, considerado portanto como um local de sobrevivência da cultura irlandesa original, autóctone, anterior à invasão e colonização inglesa - realizada por Synge foi um dos fatores determinantes para as várias temporadas de verão que Clarke passaria em Inishere, a menor das ilhas, na sua juventude. Entre o final do século XIX e o início do século XX, o oeste da Irlanda, em especial o Gaeltacht - a região onde o gaélico era o idioma predominante -, era uma fonte de inspiração para artistas e escritores em busca da essência irlandesa, distante das influências britânicas, de forma que as visitas a essa região foram fundamentais para a criação do Irish Revival. As viagens de Clarke às ilhas Aran foram realizadas na companhia de amigos como o ilustrador Austin Molloy - especialmente atuante junto ao periódico nacionalista Sinn Féin, ligado ao partido político de mesmo nome e editado por Arthur Griffith, o principal nome do movimento - e Seán Keating, pintor romântico-realista que retratou de forma heroica os habitantes das ilhas Aran e que é considerado o grande pintor da guerra pela independência irlandesa (HELMERS, 2016, p. 48-49). Estas amizades denotam que, apesar de Clarke se declarar neutro nas questões políticas (BOWE, 2015, p. 204), ele estava socialmente envolvido com pessoas diretamente atuantes na luta nacionalista, embora se posicionasse - de forma semelhante ao escritor J. M. Synge - de maneira crítica, e mesmo irônica, com relação às posturas mais românticas do nacionalismo irlandês.

J. M. Synge, junto com W. B. Yeats, Lady Gregory e o poeta, teórico e pintor simbolista George William Russell (conhecido como "AE"), tinha sido um dos fundadores do Abbey Theater: criado em 1904 como um verdadeiro teatro nacional irlandês - papel que cumpre até os dias de hoje -, o Abbey apresentou, nas primeiras décadas de seu funcionamento, peças que se encaixavam em duas vertentes principais: dramas de caráter idealista e simbolista e peças de caráter mais realista e social. A obra de J. M. Synge, no entanto, superaria esta oposição dualista, confundindo as dimensões realista e simbolista:

Synge wrote of Irish peasantry and was a founder of the Abbey with Yeats and Lady Gregory, but his work confounds the realist-idealist aesthetic divisions of that theatre. Unlike many of his fellow Protestant playwrights, he resisted "a purely fantastical, unmodern, ideal, spring-dayish, Cuchulanoid National Theatre" [...] (MCDONALD, 2014, p. 55). ${ }^{11}$

\footnotetext{
9 "Eu sei exatamente como me sinto acerca de Yeats e não consideraria o negócio por um só instante se achasse que teria que me adequar de qualquer forma às suas visões sobre a "Arte" e seu matraquear sobre composição e cor" [T.L.].

10 "Ele era um decadente no sentido decorativo, simbolista, gótico, mas sem o simbolismo profético de Yeats" [T.L.].

11 "Synge escrevia sobre o campesinato irlandês e foi um dos fundadores do Abbey com Yeats e lady Gregory, mas a sua obra confunde as divisões da estética realista-idealista daquele teatro. Diferentemente de muitos dos seus colegas dramaturgos protestantes, ele resistia 'um Teatro Nacional puramente fantástico, não-moderno, ideal, primaveril e cuchulanóide" [T.L.].
} 


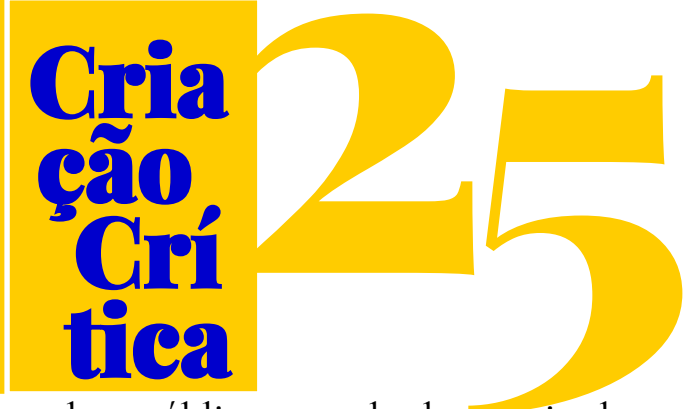

A postura crítica de Synge tinha sido motivo para desordem pública quando da estreia da sua peça The playboy of the western world em 1907, quando o público, incitado por nacionalistas irlandeses de postura mais conservadora, invadiu o palco e interrompeu a peça, atacando fisicamente os atores e dando início a um tumulto que se estendeu do teatro para as ruas de Dublin, e que só seria interrompido pela ação da polícia. A peça retrata um grupo de camponeses de uma vila no empobrecido condado de Mayo - um dos mais atingidos pela grande fome de 1845-1849, a famosa "fome das batatas" - de forma irônica e mordaz: o principal cenário é a taberna local em que trabalha a jovem Pegeen Mike Flaherty, frequentada por personagens com variados graus de intoxicação alcoólica. Quando chega à taberna de Pegeen Mike um jovem andarilho, Christy Mahon, desesperado por ter assassinado o pai - o que, ao final da peça, revela-se ser um engano, o que não foi visto pelo público da estreia em 1907, interrompida pelos distúrbios -, ele passa a ser considerado um herói por todos os habitantes do lugar, que desejam vê-lo livre da justiça britânica. Christy Mahon também desperta o desejo das mulheres do lugarejo, especialmente por parte de Pegeen Mike, que acaba desprezando o noivo em favor do recém-chegado. O público da época enfureceu-se com a representação do campesinato irlandês como apoiadores do parricídio, bêbados e imorais; segundo Declan Kiberd,

The stock explanation of the riots is that nationalists rejected a work which appeared to satirize a drunken, amoral peasantry at a time when all patriotic dramatists of the National Theatre were expected to celebrate a sturdy people ready for the responsibilities of self-government (KIBERD, 1996, p. 168). ${ }^{12}$

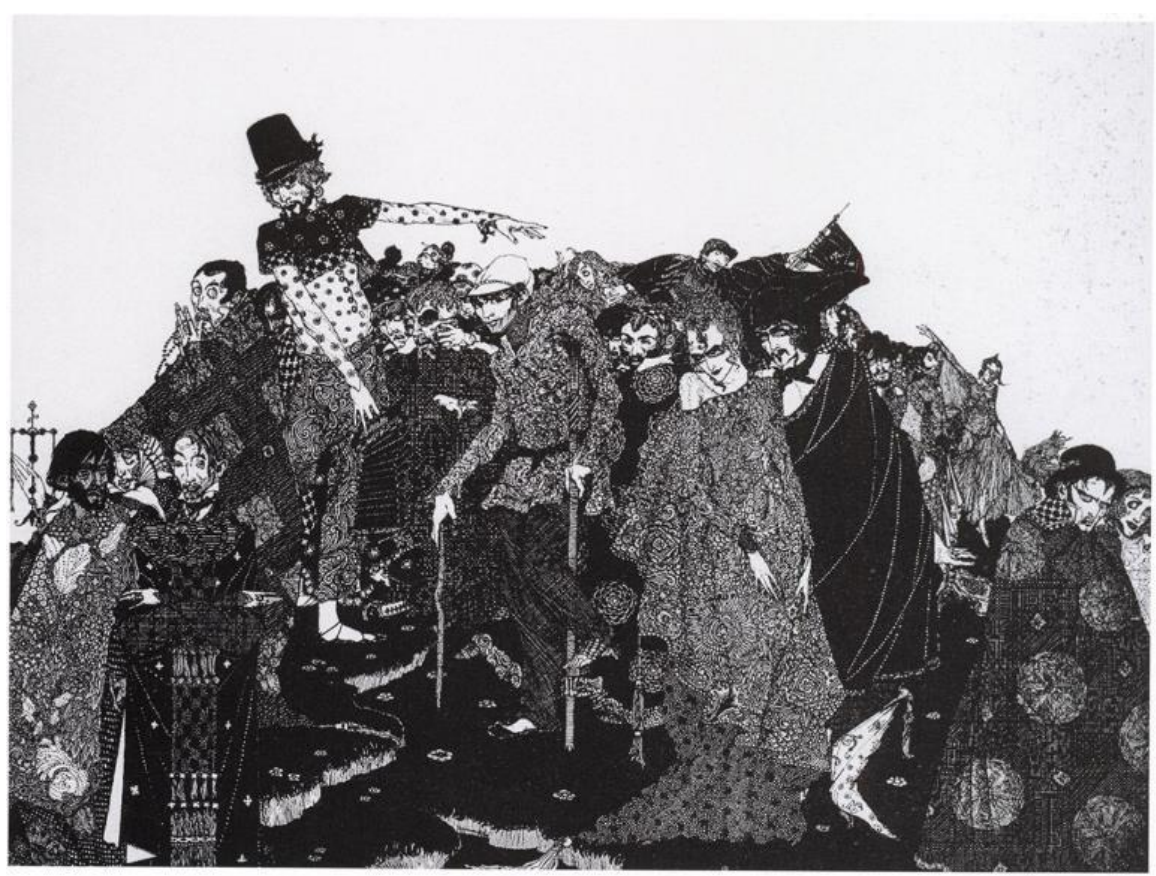

Fig.7. Harry Clarke, ilustração para The playboy of the western world, 1917.

\footnotetext{
12 "A explicação usual para os tumultos é que os nacionalistas rejeitaram uma obra que parecia satirizar um campesinato bêbado e amoral em uma época em que se esperava que todos os dramaturgos patrióticos do Teatro Nacional celebrassem um povo robusto e pronto para as responsabilidades do autogoverno" [T.L].
} 


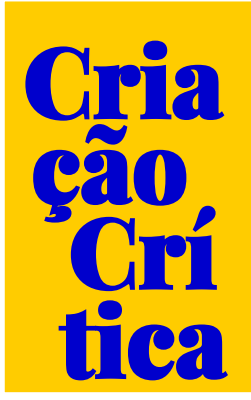

alguns dos seus trabalhos, em uma radicalização dos aspectos simbolistas que o aproxima das inovações do modernismo. Em termos literários, o Irish Revival, com suas pretensões nacionalistas de recuperar aspectos culturais da ancestralidade celta, e o modernismo, de viés mais iconoclasta, foram considerados por muito tempo mutuamente excludentes; estudos mais recentes, no entanto, como aponta Rónan MacDonald, constatam elementos comuns na sua origem (MACDONALD, 2014, p. 59). Na ilustração literária de Harry Clarke, isso ocorre pela hiperbolização dos elementos grotescos, já presente nas ilustrações para Edgar Allan Poe, e especialmente visível nas suas ilustrações para o Fausto de Goethe, publicadas em 1925, que merecem uma análise mais aprofundada que não é possível nos limites deste artigo, mas de que apresentaremos alguns exemplos no intuito de demonstrar a incipiente modernidade da sua obra.

A hiperbolização do grotesco é evidente na vinheta que antecede a cena na "Taberna de Auerbach" (fig. 8), em que Clarke se utiliza de um procedimento formal presente na arte hibérnicosaxã dos manuscritos irlandeses medievais - o preenchimento de uma forma geométrica regular com elementos curvilíneos, intrincados e irregulares -, abarrotando a forma em meia-lua, como o tímpano de uma igreja românica, com corpos distorcidos e grotescos, aludindo, assim, ao desregramento dos prazeres sensuais da comida e da bebida. As anatomias impossíveis tornam-se assim uma representação de elementos de ordem espiritual e psicológica, como bem percebeu AE Russell, um dos poucos críticos que parece ter compreendido as ilustrações de Clarke para o Fausto na época do seu lançamento:

It is the soul inside the body rather than the external form which is symbolised in the decoration to the scene in Auerbach's cellar, where one can almost hear grunt or whinny from creatures already become half-animal to the spiritual vision (RUSSELL, 1938, p. 280). ${ }^{14}$

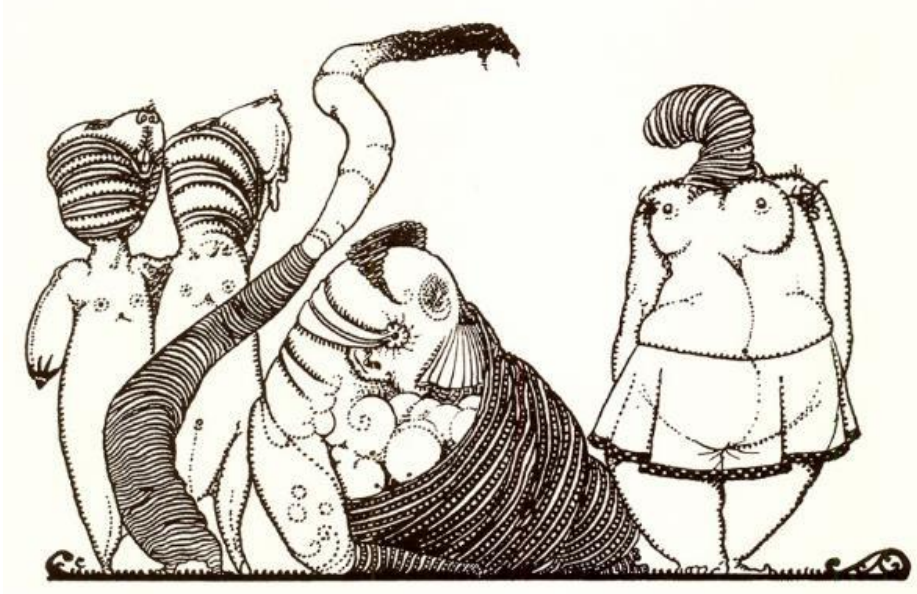

Fig. 9. Harry Clarke, ilustração para Fausto, 1925.

As imagens para o Fausto estão repletas, assim, de referências aos prazeres sensoriais desregrados, à sexualidade ameaçadora - temas caros ao decadentismo -, graficamente materializados como uma natureza doentia, perversa, putrefata, ligada a seus aspectos espirituais de

\footnotetext{
14 "É mais a alma dentro do corpo do que a forma externa que é simbolizada na decoração da cena na taberna de Auerbach, onde pode-se quase escutar um grunhido ou um guincho das criaturas já tornadas meio animais para a visão espiritual." [T.L.]
} 


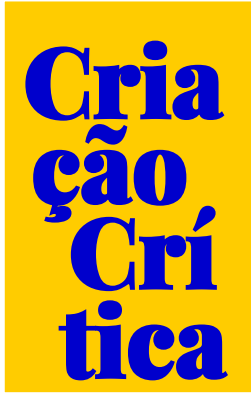

decadência e corrupção ocasionados pela influência maléfica de Mefistófeles: na vinheta que abre a cena da "Cozinha da bruxa" (fig. 9), por exemplo, vê-se uma sequência de corpos deformados e monstruosos, referência à distorção das leis naturais que será perpetrada através da magia. A cena é importante na estrutura do enredo, pois é na cozinha da bruxa que Fausto toma o elixir que o tornará jovem novamente - violação das regras naturais que parece encontrar eco na representação ambígua e grotesca dos seres que participam da cena. No seu excelente estudo sobre o horror, Noël Carroll (1999) emprega os conceitos de impureza e intersticialidade categorial para abordar as entidades monstruosas que habitam este gênero artístico. Segundo Carroll, o monstro é impuro e repulsivo por atravessar as fronteiras entre categorias profundamente enraizadas na cultura: a forma mais simples desta intersticialidade categorial é a mistura entre diferentes espécies biológicas, que se estende para formas mais sofisticadas, como a mistura entre as oposições dentro/fora ou coisas informes: "objetos também podem provocar dúvidas categoriais por serem representantes incompletos de sua classe, como coisas podres e em decomposição, bem como por não terem forma, como a sujeira" (CARROLL, 1999, p. 50). É através da construção destas biologias impossíveis e monstruosas que Clarke evoca o satanismo, tema caro ao simbolismo, que nas ilustrações para o Fausto é incorporado à própria forma de estruturação das figuras, gerando uma imagem "mefistofélica" em sua própria concepção e execução.

Assin, se Clarke havia ilustrado Poe no espírito do Des Esseintes de J.-K. Huysmans, ele ilustra o Fausto com espírito mefistofélico, impondo à imagem um móvel poético deformante, macabro e blasfemo que gera figuras monstruosas e perturbadoras, como a que representa Mefistófeles como um pênis zombeteiro que penetra uma vagina estilizada, na vinheta que encerra a cena "Floresta e gruta" (fig. 10). A figura não representa nada de material, fugindo a qualquer registro mimético mais imediato, empregando os elementos gráficos e figurativos de forma autônoma, explorando os aspectos decorativos do grafismo preciosista, repleto de detalhes microscópicos para compor uma imagem alucinante e irreal.

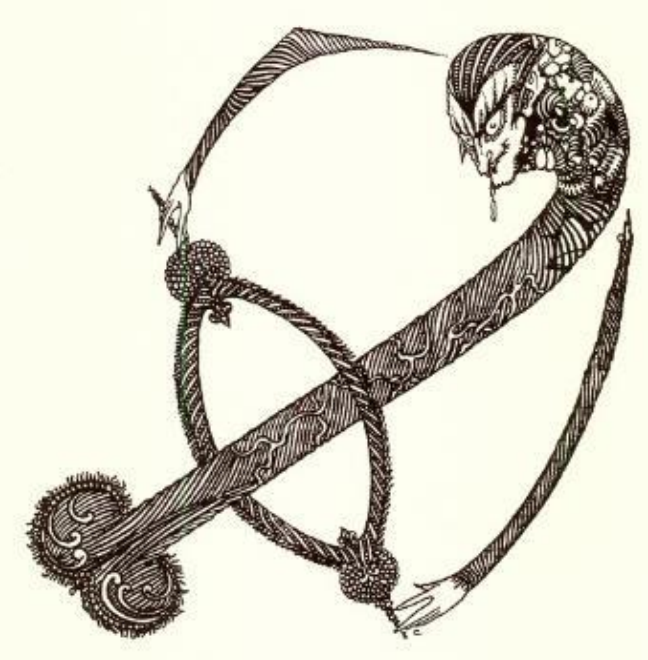

Fig. 1. Harry Clarke, ilustração para Fausto, 1925.

No texto de Goethe, a cena representa um diálogo em que Fausto manifesta o seu anseio de sondar o "fundo seio" da "infinita natureza" (GOETHE, 2004, p. 389), obtendo assim um 
Literatura e artes visuais: entre o lisível e o visível

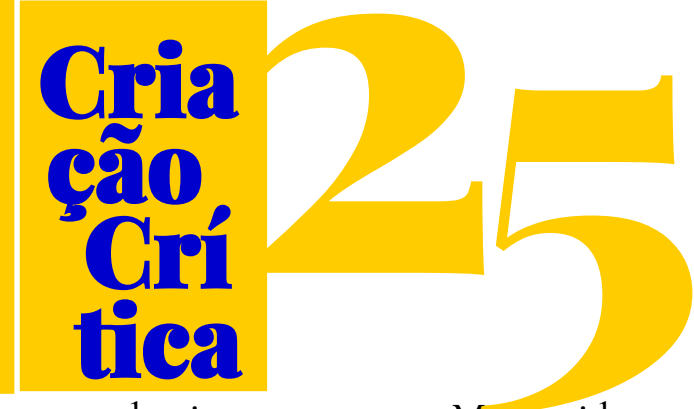

conhecimento superior e direto da realidade, agora misturado ao seu desejo amoroso por Margarida; Mefistófeles, porém, ironiza as suas altas pretensões com metáforas lúbricas:
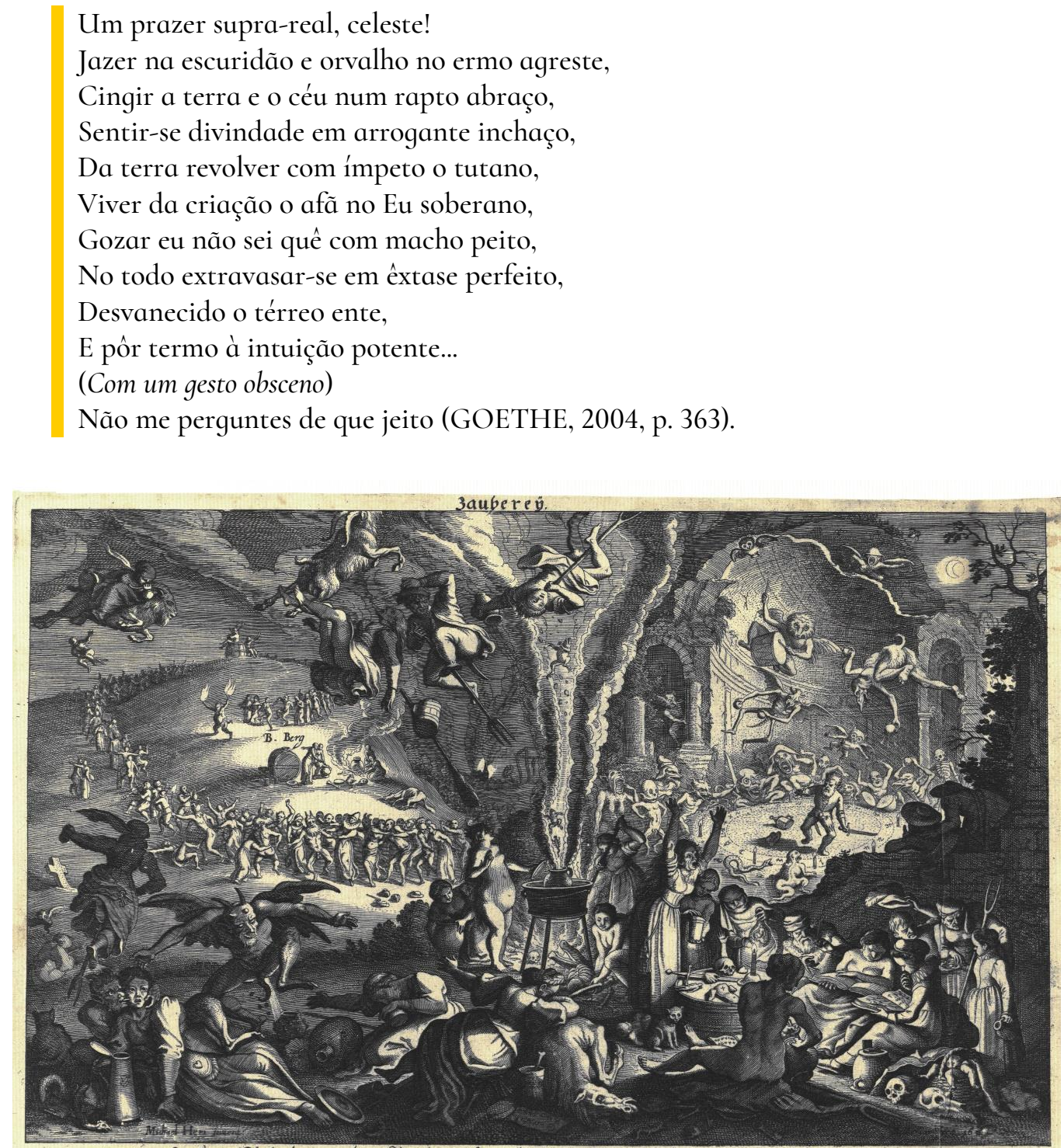

Fig. 11. Michael Herr, Verdadeiro esboço e representação da festa amaldiçoada e ímpia dos feiticeiros. Gravura, 1626.

A majestosa composição de página dupla que representa, então, a "Noite de Valpúrgis" (fíg. 12) - a reunião das bruxas para a qual Fausto é levado por Mefisto, que deseja afastá-lo das agruras por que passa Margarida, abandonada grávida pelo amante e depois condenada por matar o próprio filho - é uma verdadeira apoteose do grotesco, figurando uma multidão de seres disformes que seguem a figura monstruosa montada sobre uma porca voadora. É bastante possível que entre as fontes de Clarke para esta ilustração inclua-se a gravura de Michael Herr de 1626 - pertencente ao acervo do British Museum desde 1880 e, portanto, acessível para Clarke, que visitava a capital inglesa com frequência -; de acordo com comentadores, a gravura de Herr teria servido de inspiração para Goethe para a criação da cena (cf. MAZZARI in GOETHE, 2004, p. 433). Intitulada Verdadeiro esboço e representação da festa amaldiçoada e ímpia dos feiticeiros (fig. 11), a gravura apresenta vários elementos das crenças populares acerca das reuniões de bruxas, feiticeiros, demônios e outros entes 
Literatura e artes visuais: entre o lisível e o visível

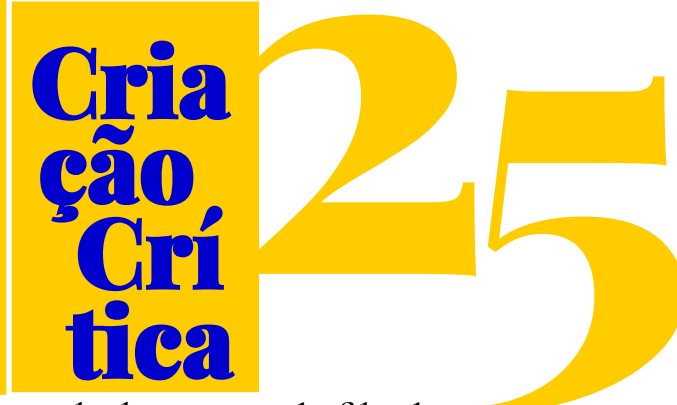

diabólicos, com vários aspectos comparáveis aos empregados por Clarke: a grande fila de pessoas em variadas atitudes que sobe a montanha, à esquerda; o turbilhão formado pela fumaça que se eleva da região central inferior da imagem, evolando-se para os dois lados da composição; além, é claro, da profusão de figuras bizarras e diabólicas, são elementos em comum entre as duas imagens. A ênfase de Clarke, no entanto, é nas figurações anatômicas disformes e repugnantes, com uma atenção especial aos aspectos sensuais e provocantes. À frente do monstruoso cortejo, vê-se Baubo, montada sobre uma porca grávida, como referida no texto:

VOZ

A velha Baubo vem sozinha;

Numa porca-mãe se avizinha.

CORO

Honra, pois a quem honra cabe!

A velha à frente, já se sabe!

Porca robusta e anciã peralta,

Das bruxas segue toda a malta (GOETHE, 2004, p. 445).
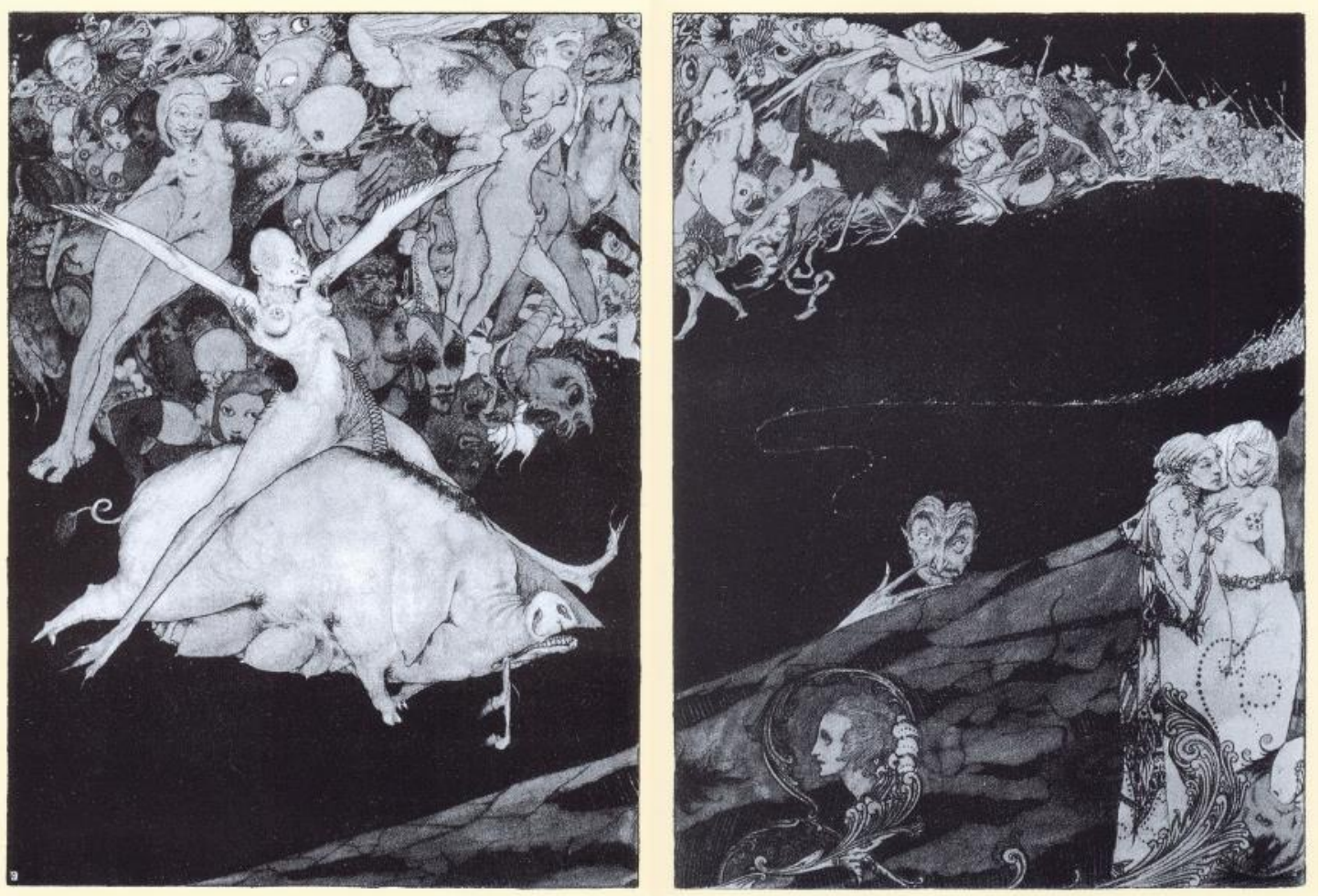

Fig. 12. Harry Clarke, ilustração para Fausto, 1925.

Baubo, na mitologia grega, é a velha criada de Deméter que, para distraí-la da tristeza causada pelo rapto da filha, Perséfone, mostra-lhe a vulva e narra histórias devassas e cômicas, provocando seu riso. Suas representações artísticas na Antiguidade incluem a figuração como um estranho ser desprovido de cabeça, em que o rosto se situa no ventre e o queixo na região da vulva; outra de suas manifestações iconográficas é a de uma mulher corpulenta com as pernas abertas, no 


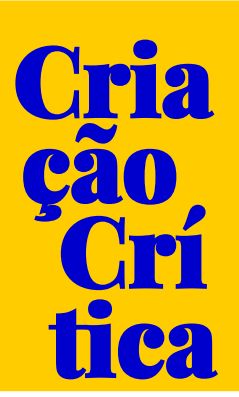

ato de exibir a genitália. Clarke representa Baubo em atitude análoga, com as pernas abertas sobre a bizarra porca; no seu corpo híbrido, em que as mãos se parecem com asas atrofiadas e o rosto tem estranhas proporções, a região da genitália é ocupada por um grande rufo, elemento do vestuário entre os séculos XVI e XVII que funcionava como sinal de distinção e nobreza e que aqui estabelece a estranha ambiguidade sexual da personagem (fig. 12). O rosto de Mefisto aparece, com expressão curiosa, por trás das rochas que preenchem o espaço inferior, delimitado em diagonal ascendente. No canto inferior direito, um estranho casal parece envolvido em uma conversa íntima, sugestão do flerte entre Fausto e a "Beldade", uma jovem e atraente bruxa, assim encenado no texto de Goethe:

FAUSTO (dançando com a jovem)

Um lindo sonho outrora tive;

Numa macieira me detive,

Duas maçãs lhe espiei, tão belas,

Que na árvore trepei, por elas.
A BELDADE
Já as maçãs nas férteis hastes
Do jardim do Éden almejastes.
Quanta alegria sinto em mim,
Por ter iguais em meu jardim (GOETHE, 2004, p. 461).

Na seção inferior da mesma imagem, um retrato feminino em perfil, circundado por uma moldura, sugere a lembrança de Margarida que retorna à mente de Fausto, malgrado os excessos sensoriais e as tentações proporcionadas pelo sabá das bruxas: a imagem manifesta, assim, mais uma contraposição entre o belo, representado por Margarida, com seu perfil clássico e harmonioso, e o grotesco desfile de uma miríade de seres disformes e caricatos, enquanto o rosto zombeteiro de Mefistófeles assiste ao flerte entre Fausto e a beldade. No seu conjunto, a imagem se conforma como uma colagem de elementos díspares, sem conformar um espaço figurativo unitário. A imagem representa um mundo fragmentado e insólito, como aliás é sugerido pelo texto: sintetizando os diferentes momentos da "Noite de Valpúrgis", no entanto, Clarke emprega o grotesco junto ao grafismo decorativo para criar uma imagem que, ao fugir da unidade estrutural da figuração tradicional, estabelecida desde o Renascimento, aponta para a autonomia da realização plástica e para o abandono da qualidade mimética da figuração. A sensualidade ameaçadora, identificada com o diabólico, é o principal elemento que materializa o discurso mefistofélico no tema e na forma: radicalizando o simbolismo e, principalmente, o decadentismo que perpassa toda a sua obra, portanto, as imagens para o Fausto representam a modernidade de Clarke em seu momento de eclosão. O olhar de hoje talvez o associaria, impropriamente, às formas fantásticas e inquietantes do Surrealismo, cujo primeiro manifesto foi publicado em Paris em 1924, provavelmente na mesma época em que o ilustrador irlandês produzia estas imagens; não há, no entanto, nenhuma documentação que ateste qualquer contato entre Clarke e a vanguarda francesa, e qualquer suposição neste sentido parece pouco razoável.

O modernismo nascente de Harry Clarke surgiu, portanto, a partir dos próprios fermentos simbolistas presentes na sua obra, da sua proximidade com os autores literários da sua época e da sua interpretação visual de um clássico literário (dentre outros ilustrados por Clarke) como o Fausto de Goethe, interpretação essa que o trazia para uma visualidade contemporânea e inovadora. As inquietantes e fantásticas biologias mefistofélicas das imagens para o Fausto, repletas de erotismo e 
